\title{
Ensino mútuo e independência no Brasil
}

\section{Mutual education and independence in Brazil}

Wojciech Andrzej Kulesza

Orcid: http://orcid.org/0000-0001-6882-1516

Universidade Federal da Paraíba, João Pessoa,

Brasil, wakulesza@gmail.com

DOI: $10.21680 / 2596-0113.2021 v 4 n 0 I D 25315$

Citation: Kulesza, W. A. (2021). O Ensino mútuo e independência no Brasil. History of Education in Latin America - HistELA, 4, e25315.

Competing interests: The authors have declared that no competing interests exist.

Editor: Olivia Morais de Medeiros Neta

Received: 21/05/2021

Approved: 02/07/2021

\section{OPEN ACCESS}

\begin{abstract}
Resumo
Introduzido na América Latina em pleno processo de independência política da região, o método de ensino mútuo constituiu uma primeira tentativa de organizar a educação elementar nas novas nações emergentes no continente. Encarado como a solução mais econômica e eficaz para a escolarização do povo, o método configurou para os governantes das décadas iniciais do século XIX, um modelo de escolarização adequado à realidade póscolonial. Neste trabalho procuramos descrever as iniciativas de aplicação do método do ensino mútuo visando a educação elementar dos brasileiros, a partir do momento em que se descortinava a emancipação do país. Com ênfase especial no papel dos condicionantes econômicos, sociais e políticos postos ao Estado em formação para estruturar o ensino oferecido à população, a análise ressalta a adequação do método para a formação da nacionalidade naquele momento histórico.
\end{abstract}

Palavras-chave: Educação Popular. Escolarização. Estado Nacional.

\begin{abstract}
Introduced in Latin America during the region's struggles for national independence, the method of mutual education was a first attempt to organize elementary education in the new emerging countries on the continent. Seen as the most economical and effective solution for the education of the people, the method configured for the government of the early decades of the 19th century, a model of schooling appropriate to the post-colonial reality. In this work we try to describe the initiatives of application of the method of mutual education aiming at elementary education of Brazilians, from the moment when the emancipation of the nation was unveiled. With special emphasis on the role of economic, social and political constraints placed on the State in formation to structure the education offered to the population, the analysis highlights the adequacy of the method for the formation of nationality at that historic moment.
\end{abstract}

Keywords: Popular Education. Schooling. National State.

\section{Introdução}

A transição no Brasil da condição de colônia de Portugal para uma nação soberana exigiu a organização de um Estado nacional. Esse processo se iniciou pela adaptação da estrutura do Estado português, quase toda transplantada para a 
América com a vinda de D. João VI para o Brasil em 1808, à realidade da sociedade colonial. Antes mesmo da independência política de 1822, o processo de interiorização da metrópole lusitana no Brasil, coroado pela elevação da colônia a Reino Unido em 1815, já havia implantado na realidade brasileira a maioria dos órgãos da administração portuguesa com toda sua burocracia característica. Essa herança organizativa inicial foi determinante no aparelhamento do Estado brasileiro a partir do 7 de setembro, marcando profundamente nossas instituições, especialmente nos anos iniciais da independência.

Por sua vez, o apoio político e militar da Inglaterra nessa transposição da Corte portuguesa para o Rio de Janeiro resultaria, no plano econômico, na transferência da dependência que a colônia brasileira tinha de Portugal para o império britânico. Esse movimento geopolítico, fortemente influenciado pelas exigências postas pela revolução industrial inglesa, terminaria por sacudir, tanto na América como no Continente, a estrutura política ibérica, remanescente do Antigo Regime. A insurgência em territórios do reino português, tanto da revolução do Porto de 1820, como da independência do Brasil em 1822, bem no meio do período denominado por Hobsbawm de "era das revoluções", indica a crescente incorporação ao mundo luso do processo de internacionalização do capitalismo industrial no Ocidente a partir do século XIX.

A afirmação do liberalismo no campo econômico se estendeu a outras esferas da vida social, como mostra o significativo respaldo da legitimidade do princípio de representação política da população, base da construção dos sistemas de governo, tanto da monarquia constitucional, como da república. A forte presença do Estado em todos os setores sociais, estabelecida anteriormente pelo despotismo ilustrado de Pombal, pouca afetada pela "viradeira" que restabeleceria o poder real após seu afastamento do governo, seria revisada tão logo a abertura dos portos brasileiros "às nações amigas" acabou com a exclusividade que os comerciantes portugueses desfrutavam no mercado colonial para seus produtos e para as mercadorias adquiridas de outros países. O favorecimento dado ao comércio inglês por diversos tratados diplomáticos entre a Inglaterra e Portugal, tornava inviável a concorrência dos comerciantes reinóis, qualquer que fosse a ajuda que o Estado português pudesse Ihes dar.

As ideias liberais foram permeando a estrutura do Estado favorecendo as investidas da iniciativa privada. Com a Proclamação da Independência, ao se colocar a necessidade concreta do estabelecimento de uma nação brasileira autônoma, boa parte do aparelhamento do Estado anterior seria recuperado e aproveitado, em todo ou em parte. As instituições educacionais, pela sua importância na formação do povo da nova nação, bem como na preparação de seus quadros dirigentes, seriam logo focalizadas na Assembleia Constituinte e Legislativa de 1823. A criação de universidades e a educação popular, os "estudos superiores" e os "estudos menores", seriam objeto de discussão acalorada, interrompida com a dissolução da Constituinte. Com a retomada dos debates, com base nessas discussões, seriam criadas posteriormente as Faculdades de Direito de Olinda e São Paulo em 11 de agosto 1827 e a primeira lei geral do ensino em 15 de outubro do mesmo ano.

Se a criação das escolas jurídicas e mais algumas alterações nas escolas superiores estabelecidas por D. João VI desde sua chegada ao Brasil, preencheu satisfatoriamente a necessidade do Estado de preparar os profissionais que iriam trabalhar na área médica, jurídica e militar da nova nação, a educação elementar, ao menos vista retrospectivamente, continuou a trajetória de descaso, miséria, improviso e desorganização herdada do período colonial, se não da própria metrópole. No que se segue procuramos descrever e analisar as propostas sugeridas e ações 
efetivamente tomadas visando a educação elementar dos brasileiros a partir do momento em que se descortinava a emancipação do país. Ênfase especial será dada ao papel dos condicionantes econômicos, sociais e políticos postos ao Estado em formação para organizar o ensino oferecido à população.

\section{O período joanino}

A presença do soberano português no Brasil a partir de 1808 tornou ainda mais semelhantes os "estudos menores" no Brasil e em Portugal. Continuavam funcionando as aulas régias, com a criação de escolas e a nomeação de professores a cargo da Coroa, ainda financiadas pelo "subsídio literário" introduzido por Pombal em 1772 e atualizado, já em fevereiro de 1808, para ser aplicado ao comércio de aguardente no Brasil (Tonholli, 2016, p. 52). O estabelecimento de uma fonte de recursos própria assinala a criação de um lugar autônomo para a educação pública no Estado português. Ao mesmo tempo, continuavam também as diversas ações educativas da Igreja Católica, que não incluíam somente a formação de seus próprios quadros, em seminários e conventos, mas que se desenvolviam em conjunto com o trabalho de catequese e evangelização. Devido à instituição do padroado, essas ações eram financiadas pelo recolhimento da dízima, fazendo dos padres seculares uma espécie de funcionários do Estado, enquanto o clero regular se mantinha com os recursos das respectivas ordens religiosas, o que não significa que não se valesse de vultosos subsídios do Estado, especialmente quando se tratava de erigir suas suntuosas edificações.

Uma outra presença do Estado na educação portuguesa se deu através da Secretaria de Estado dos Negócios da Guerra, que virá assumir particular importância nesse período beligerante, por meio das aulas para a formação militar específica, como a pioneira Aula de Artilharia e Fortificações posta a funcionar no Rio de Janeiro no início do século XVIII (Valente, 1999, p. 43). A realidade da guerra para conter a invasão francesa de Portugal, que só terminou em 1811 graças ao providencial reforço da armada e do exército inglês, deixou claro o desconhecimento por parte dos militares portugueses das novas armas e táticas utilizadas nas guerras napoleônicas e o despreparo dos soldados em manejá-las. Compreender instruções escritas, se comunicar, descrever acuradamente a quantidade de armamentos e munições, 0 número de inimigos, eram agora tarefas imprescindíveis de todo soldado. Saber ler, escrever e contar, passou a ser tão fundamental nos campos de batalha, quanto o vigor físico.

Após algumas experiências isoladas nos quartéis, o príncipe regente resolve institucionalizar essa espécie de aulas por meio de portaria datada de 10 de outubro de 1815 na qual o ainda príncipe regente determina:

desejando promover nos corpos de linha do seu exército o conhecimento da leitura e escrita portuguesa, não só para bem dos serviços dos mesmos corpos, economia da sua real fazenda, mas também para benefício daqueles seus vassalos que pretendem ocupar os diversos postos militares na classe de oficiais inferiores. É servido mandar estabelecer uma aula de ler, escrever e contar, em cada corpo de infantaria, caçadores, cavalaria e artilharia do seu exército, e na real guarda da polícia de Lisboa, a fim de que se aproveitem delas os indivíduos dos mencionados corpos, querendo eles, e igualmente seus filhos, assim como também os filhos dos habitantes das terras ou bairros em que os mesmos corpos tiverem os seus quartéis (Carvalho, 2011, p. 525-526). 
O projeto estava bem amadurecido, pois no mesmo dia, saem as Instruções para o estabelecimento e direção das escolas mandadas criar pela portaria evidenciando "tratar-se de um plano de desenvolvimento dessa categoria de escolas, avultando nele a envergadura da respectiva rede" (Fernandes, 1999, p. 28). As aulas referidas na portaria eram somente para começar, pois planejava-se fundar 53 escolas e a utilização de 106 docentes (um mestre e um ajudante em cada uma). $\mathrm{Na}$ apreciação de outro historiador português, a ideia desse projeto poderia ter constituído

um acontecimento de relevo, uma providência de grande amplitude e alcance, pioneira da educação entre nós, capaz de movimentar o país inteiro em toda parte onde houvesse quartéis, num profícuo combate ao analfabetismo extremamente elevado entre nós, com possibilidades de ser realmente proveitosa (Carvalho, 2011, p. 526).

Todavia, ainda segundo esse mesmo autor, não se tratava de um "ambicioso plano pedagógico", mas apenas uma apropriação do que viria a ser chamado de ensino mútuo ou monitorial, muito em voga naquele momento e fartamente propagandeado pela oficialidade inglesa presente no exército português. Segundo ele, o governo luso solicitou à aliada Inglaterra o envio de alguém capaz de organizar o exército de Portugal para repelir as investidas dos ingleses. O general Beresford foi enviado e logo nomeado generalíssimo do exército português. Com o fim das invasões francesas, Beresford manteve seu cargo, focando-se agora nos inimigos internos da realeza, ou seja, os portugueses que batalhavam por um regime constitucional, vitoriosos em 1820. Como, para fazer esse serviço, precisava da anuência do Rei, viajou para o Rio de Janeiro em agosto de 1815, lá permanecendo até setembro de 1816, portanto, tendo tido a oportunidade de ser o "informador e instigador da criação das referidas escolas (Carvalho, 2011, p. 527-528).

Será também por iniciativa da Repartição dos Negócios da Guerra que seria introduzido o método de ensino mútuo no Brasil a partir de 1820, com a criação de uma escola de ensino mútuo na Corte junto ao Arsenal do Exército. Essas iniciativas teriam continuidade depois do Sete de Setembro, oficializando-se essa escola por decreto de 1ํㅡㄹ março de 1823 e abrindo-a "a todas as classes de meus súditos que queiram aproveitar-se de tão vantajoso estabelecimento" (apud Bastos, 1999, p. 109). A generalização do método para todas as escolas seria afirmada pela portaria datada de 29 de abril de 1823, na qual Pedro I determinou a instrução pelo ensino mútuo, "não só dos Corpos Militares, como em geral de todas as outras classes", estando o imperador persuadido

de quanta utilidade seria criar-se neste Império Escolas de Ensino Mútuo pelo Método de Lancaster, as quais espalhando na Europa inumeráveis bens, pudessem igualmente ser profícuas, neste abençoado País, desenvolvendo o espírito e preparando-o para novas aquisições de mais transcendentes ideias (apud Cardoso, 1999, p. 122-123).

Aqui como em Portugal o projeto era grandioso, contemplando todo o império e solicitando aos governos provinciais que enviassem

para esta Corte um ou dois indivíduos tirados da Tropa de Linha, sejam da classe de Oficiais Inferiores, sejam dos Soldados, que tenham a necessária e conveniente aptidão para aprenderem o mencionado método e poderem, voltando a sua Província, dar lições 
não só aos seus irmãos d'armas, mas ainda às outras classes de cidadãos (apud Cardoso, 1999, p. 123).

Vê-se assim que, apesar da escola a ser criada na Corte não ser nominada como Escola Normal, isto fica subentendido no decreto, o que explicaria a questão levantada por Cardoso (1999, p.122) de porque o decreto de 1829 extinguiu "a Escola Normal do ensino mútuo que foi servido criar nesta Corte por Decreto de $1^{\circ}$ de março". Essa portaria reafirma também a intenção do governo de estender a escolarização oferecida por essas escolas às comunidades circunvizinhas dos quartéis. Apesar da afluência tanto de adultos, como de jovens e crianças a essas escolas nos quartéis, dadas as características deste ensino elementar, voltado diretamente para as atividades realizadas nos quartéis, nos parece puramente acidentais os benefícios trazidos por elas para as comunidades. Claudia Alves, conclui seu trabalho sobre a presença militar na educação brasileira no século XIX, afirmando que "o exército findou por tornar-se uma grande agência de educação escolar na sociedade imperial" (Alves, 2003, p. 249). Se isso pode ser aplicado com certeza às escolas secundárias e superiores mantidas pelo exército, o mesmo não se pode dizer em relação às escolas de primeiras letras.

Não há dúvida que o chamado ensino mútuo, popularizado com esse nome na França, ou monitorial, denominação mais utilizada na Inglaterra, tenha sido a inspiração dessas iniciativas de ensino junto ao exército português, tanto na metrópole como no ultramar. Fruto direto do iluminismo francês e do liberalismo inglês, o método teria se iniciado no final do século XVIII com a experiência educacional do pastor anglicano André Bell, num orfanato que abrigava filhos de militares numa colônia inglesa na Índia, seguido pela criação em Londres de uma escola para crianças pobres pelo quaker José Lancaster, que sistematizou sua experiência em livro . O sistema atendia perfeitamente as necessidades de formação das massas, tanto do ponto de vista do conteúdo elementar, quanto da desejável preparação disciplinar para enfrentar as novas relações de trabalho na indústria.

\section{A escalada do ensino mútuo}

A rápida difusão do método de Bell e Lancaster no início do século XIX se deve em grande parte à iniciativa privada. Na França, a Société d'Encouragement pour l'Industrie Nationale, criada em 1801, para a qual "a educação é o primeiro meio de formar os homens de virtude, amigos da ordem e submissos às leis, inteligentes e trabalhadores", logo daria origem à Société pour l'Instruction Élémentaire, especializada no fomento à instalação de escolas de ensino mútuo (apud Bastos, 1999, p. 102). No âmbito dessa sociedade foi criada uma escola normal de ensino mútuo em Paris e editada uma revista pedagógica, o Journal d’Éducation, que servia de canal de comunicação entre as centenas de escolas assim criadas a partir de 1815, ao mesmo tempo que propagandeava o método no país e no exterior. Como expressão inequívoca do imperialismo francês, o periódico instalaria em 1818 um "comitê de correspondência com as escolas estrangeiras", a fim de "expandir um exemplo que é grande, liberal e útil (...) de propagar indistintamente um método, os benefícios, e contribuir à expansão de nossa língua e de nosso comércio" (apud Bastos, 1999, p. 105).

Claramente, o sucesso do método repousava sobre sua possibilidade de proporcionar uma educação popular rápida, importante por liberar logo as crianças 
para o trabalho, e de baixo custo, essencial para atingir um grande número de indivíduos. Do ponto de vista social, o método fornecia a educação demandada pelos novos modos de produção, como bem assinalou o Conde de Lasteyrie, um dos próceres da Société em seu livro Nouveau système d' éducation et d'enseignement, publicado em Paris em 1819:

\begin{abstract}
l'enseignement mutuel est l'instruction populaire chez toutes les nations civilisées que ne voudront pas rester stationnaires, et perdre l'ascendant que donnent les arts, les fabriques, l'industrie, et l'amélioration morale des classes inférieures. Le nom de Lancaster mérite, à ce titre seul, de passer à la postérité (apud Conde, 2005, p. 118).
\end{abstract}

Examinando o periódico francês Journal d'Éducation, Bastos encontrou interessantes referências ao ensino mútuo no Brasil desde 1817. Segundo esse periódico, nesse ano teria sido enviado pelo governo a Paris um jovem professor para se instruir no método para, em seguida, implantar o ensino mútuo no país, mas são desencontradas as notícias sobre sua sorte (Bastos, 1999, p. 105). Mais consistentes são as referências às iniciativas do Conde de Scey, que estaria utilizando o método para instruir os escravos de sua fazenda e pedia que a Société lhe enviasse materiais didáticos relativos ao método, uma vez que não havia conseguido importá-los "diante das formalidades da alfândega e a censura sobre os objetos impressos". O conde francês estava pensando nos "quadros" utilizados pelas decúrias de alunos que, no método, substituíam as cartilhas individuais.

Na carta, publicada no Journal de julho de 1819, o conde, para justificar o seu pedido, carrega nas tintas para demonstrar sua fidelidade aos princípios liberais da Société:

\begin{abstract}
Eu me ocupei de comunicar no Brasil, os benefícios do ensino mútuo, fazendo principalmente a aplicação em jovens negros, de um e outro sexo, que são trazidos da costa da África, nos quais as faculdades morais são praticamente nulas. Eu já obtive resultados que prometem ser venturosos (...) A sorte dos negros é tão desgraçada que concorrer para amenizá-la entramos, sem dúvida, nos aspectos filantrópicos da sociedade. Pela instrução os negros conseguem reunir os fundos necessários para comprar a sua liberdade e a de seus filhos (apud Bastos, 1999, p. 106).
\end{abstract}

A carta é novamente citada na edição de agosto de 1819 dizendo que a Société havia enviado os materiais pedidos pelo conde. Todavia, em nova carta, publicada em agosto de 1820 no mesmo periódico, o conde se queixa de ainda não ter recebido os materiais, aduzindo mais argumentos para que isso fosse feito:

O conde de Gestas seguiu o meu exemplo em sua terra, e todos os seus escravos receberam os conhecimentos elementares sobre a língua francesa e portuguesa, educação religiosa, e ganhou muito com isso. Os plantadores vizinhos, observando a boa conduta destes negros, em que o grau de civilização aumentou a população, se apressarão com certeza em empregar os mesmos meios, quando puderem ser bem assessorados e procurar institutores (apud Bastos, 1999, p. 108).

Esse grupo de franceses bonapartistas tinham pequenas propriedades no Alto da Boa Vista no Rio de Janeiro e, apesar de plantarem café em seus sítios, não podem ser considerados grandes produtores, sendo pequeno o número de escravos que 
cada um possuía, a maioria perfazendo funções domésticas. As cartas do Conde de Scey, claramente auto elogiosas de suas ações, ilustram bem o papel "civilizador" do método e a facilidade com que qualquer pessoa letrada poderia aplicá-lo. Como francês, como o conde fez para construir os quadros em português? Seria indiferente se fazer a alfabetização em português ou francês para quem convive com uma família francesa num sítio do Rio de Janeiro? Podemos crer que a "civilização" tornou livres os cativos, ao mesmo tempo que incrementava sua reprodução?

Enquanto isso, na Inglaterra, o ensino monitorial estava sendo amplamente debatido, sendo fundada em 1814 uma sociedade, a British and Foreign School Society, intimamente associada com a protestante British and Foreign Bible Society, dedicada à criação de escolas baseadas no ensino mútuo no país e nas colônias de ultramar. A constante referência a esse método nos jornais ingleses influenciou a imprensa estrangeira presente em Londres, estendendo o debate a outros países. Assim, por exemplo, artigos tratando do ensino mútuo publicados no jornal $O$ investigador português em Inglaterra, a partir de 1815, tiveram grande repercussão em Portugal (Carvalho, 2011, p. 528), enquanto o Correio Braziliense publicou em 1816 uma série de artigos de Hipólito da Costa sobre o método de Lancaster (Lins, 1999, p. 76). Essas publicações enalteciam o método, destacavam suas vantagens, citavam sua aplicação com sucesso em vários países, aconselhando sua adoção.

Talvez devido a essa divulgação é que foi concedido pelo governo em 1820 "a João Batista de Queiroz uma pensão anual para ir à Inglaterra, aprender o sistema lancasteriano". Todavia, ele acabou indo para a Escola Normal de Paris de onde "retornou depois de ser instruído e ter se submetido aos exames" (apud Bastos, 1999, p. 108-109). A existência de uma rede de escolas de ensino mútuo na França, inclusive com o funcionamento de uma Escola Normal, estimulou o envio a Paris de professores vindos do estrangeiro para se familiarizarem com o novo método de ensino mútuo. Em Portugal, onde o ensino mútuo era bem conhecido e, inclusive, aplicado nas escolas do Exército, como vimos, o método recebe um reforço legal importante com a promulgação da Constituição Política da Monarquia Portuguesa em 23 de setembro de 1822. O artigo 239, expressão do liberalismo em matéria de educação, determinava que "é livre a todo o cidadão abrir aulas para o ensino público contanto que haja que responder pelo abuso desta liberdade nos casos e pela forma que a lei determinar" (apud Carvalho, 2011, p. 533), atendendo assim as iniciativas de fundar escolas para a educação elementar feitas por particulares, geralmente motivadas pelo "método Lancaster".

Na verdade, Dom João VI, acatando decisão das Cortes Constituintes, já havia exarado decreto neste sentido em 28 de junho de 1821 nos seguintes termos:

\footnotetext{
atendendo a que não é possível desde já estabelecer, como convém, escolas em todos os lugares deste Reino por conta da Fazenda Pública; e querendo assegurar a liberdade que todo o cidadão tem de fazer o devido uso de seus talentos, não seguindo daí prejuízos públicos, decretam que da publicação deste em diante seja livre a qualquer cidadão 0 ensino e a abertura de Escolas de primeiras letras, em qualquer parte deste Reino, quer seja gratuitamente, quer por ajuste dos interessados, sem dependência de exame ou de alguma licença (apud Cury, 2018, p. 1221).
}

Essa medida visava atender as inúmeras demandas da iniciativa privada em prover educação elementar, como é ilustrado pela disposição de alguns negociantes abastados do Rio de Janeiro que em 1816 se dirigiram publicamente ao Príncipe Regente oferecendo "voluntariamente uma subscrição para a formação de um capital 
a ser empregado em ações do Banco do Brasil, cujo rendimento anual devia ser privativa e perpetuamente aplicado para estabelecimentos que promovam a Instrução Nacional" (apud Neves, 2014, p. 171). Por isso, não é de se estranhar que a Assembleia Constituinte de 1823 no Brasil também tenha abordado na mesma chave a questão do "ensino livre" na educação elementar. Segundo Chizzotti, inspirada na lei portuguesa, foi aprovada uma lei idêntica "que ampliava as possibilidades da educação privada" (1996, p. 43).

Quando o Conselho Superior de Educação Pública de Portugal decide imitar o exemplo de outros países e fundar uma escola de professores, mirar-se-á no novo método. Para concretizar a proposta, resolve enviar a Paris, em 1823, o professor João José Lecocq para estagiar na Escola Normal de ensino mútuo de Paris durante seis meses, preparando-se assim para fundar uma Escola Normal. Na realidade, essa instituição, que viria a ser fundada em Lisboa em 1824, não se limitaria à preparação de professores para o ensino elementar, mas pretendia preparar diretores para que eles organizassem escolas normais pelo país, estas sim destinadas à formação de "mestres de primeiras letras". É interessante observar que no decreto de criação da Escola Normal, uma vez que "na dita escola, se não ensina uma ciência, mas sim um método até agora desconhecido em Portugal", se determina que ela fique "independente da Junta da Diretoria Geral dos Estudos e da sua Inspeção, até nova determinação minha em contrário". Ou seja, parece que o Estado, ao se eximir da responsabilidade de dirigir e inspecionar essa escola, age tal como um agente da iniciativa privada, apesar de, logo em seguida determinar que "os discípulos da dita escola, que unirem aos seus estudos idoneidade, aptidão e os mais requisitos para o magistério de primeiras letras, preferirão, em igualdade de merecimento, nos concursos para o provimento de tais cadeiras régias" (apud Conde, 2005, p. 193).

Oferecendo em seu início cursos de dois meses para um número reduzido de alunos-mestres, a Escola Normal de ensino mútuo terá uma trajetória atribulada, mudando ocasionalmente de lugar, mudando seus objetivos, sendo às vezes até desativada, para finalmente ser suprimida por decreto em 1869 junto com as escolas normais regionais nela inspiradas. Na justificativa desse decreto encontra-se a seguinte apreciação:

\footnotetext{
As escolas (...) de ensino mútuo, que deviam também reunir a condição de escolas normais, não satisfizeram nunca a esta parte, a mais importante da sua missão, talvez porque lho vedara a exiguidade de meios e de organização de que foram dotadas, nesta primeira tentativa de introduzir o ensino pedagógico nos domínios da instrução popular (apud Conde, 2005, p. 132).
}

\section{Difusão na américa espanhola}

Da França e Inglaterra, o movimento em prol do ensino mútuo irá se alastrar para outros países, limitando-se inicialmente apenas à propaganda difundida por jornais, folhetos e livros para, em seguida, promover o envio de seus seguidores a outros países para a implantação de escolas. Nesta época, com a transformação das colônias em nações independentes em toda América Latina, a região passa a atrair os partidários do ensino mútuo, ensejando a vinda de professores desejosos de estabelecer escolas segundo a nova doutrina. Verdadeiros missionários, termo que pode ser tomado literalmente no caso daqueles associados à evangélica British and Foreign School Society, geralmente recomendados pelas sociedades lancasterianas, 
estes pedagogos passaram a se aventurar pela região, uma vez que seu relacionamento com os nativos era pessoal, sem qualquer suporte institucional.

Este foi o caso paradigmático de James Thomson, membro da School Society que aportou em Buenos Aires em 1818 e convenceu o prefeito a estabelecer uma "sociedade lancasteriana" para difundir o ensino mútuo na cidade. Satisfazendo a necessidade de amplos espaços para o funcionamento do método, Thomson consegue que a Ordem dos Franciscanos ceda seu convento principal. Neste amplo espaço, Thomson instala uma espécie de Escola Normal para treinar os professores no método e uma escola de ensino mútuo capaz de abrigar 100 alunos. Dez meses após sua chegada, Thomson será contratado como professor da "Escola Normal" e diretor de escolas da cidade "el máximo cargo de la política educativa de la época", recebendo em 1821 uma carta de cidadania portenha (López e Narodowski, 1999, p. 45-47).

Esses autores, referindo-se ao impensável sucesso de um pedagogo protestante numa cidade católica de uma América espanhola recém emancipada, inclusive com a ajuda do clero local, destacam a neutralidade de Thomson em assuntos de religião em suas escolas, mesmo reconhecendo o proselitismo religioso de Thomson:

Pero además, Thomson no negaba - aunque tampoco lo proclamaba a los cuatro vientos - el ser membro de la Bible Society, por lo que el otro de sus objetivos consistia en la difusión del culto protestante por medio de la distribución de uma versión castellana de las Sagradas Escrituras (López e Narodowski, 1999, p. 46).

Ainda segundo esses autores, ao colocar a responsabilidade da educação em Buenos Aires nas mãos de Thomson, "el cabildo apuesta a la difusión del método de enseñanza y lo hace no a través de um funcionario del Estado, um burocrata, un político o un clérigo", acrescentando mais adiante:

\footnotetext{
Más todavia, al contrario de otros pedagogos europeos llegados a Buenos Aires unos años mas tarde, no se poseen evidencias de que Thomson fuera invitado por el Gobierno. Al contrario, es el cabildo de Buenos Aires quien aprovecha su estadía y lo contrata en el puesto más alto com que cuenta la administración local en lo referido a la política educativa (López e Narodowski, 1999, p. 49, ênfase nossa).
}

Ao deixar o ensino público sob responsabilidade da iniciativa privada, o Estado fica sujeito, como acontece com outros empreendimentos, à ação de indivíduos gananciosos que podem deixar a perder todo o trabalho realizado. Basta que as dificuldades que enfrenta o governo, políticas ou econômicas, principiem a afetar o empreendimento, que o empresário recolhe suas coisas e parte à procura de outro mercado. O ritmo rápido que se imprime na construção de todo esse sistema escolar é o mesmo que vigora uma vez iniciado seu desmantelamento. Thomson quando estava em Buenos Aires visitou Montevideo onde propagandeou o método, foi depois para o Chile e, em 1822 chega a Lima, onde foi entusiasticamente recebido pelo general San Martín, firmando com presteza um acordo

lo que incluía - como fuera usual em Buenos Aires y Santiago, las escuelas anteriores en el viaje de Thomson - el establecimiento de uma Escuela Normal bajo la dirección de Thomson, la utilización del colégio de Santo Tomás de Lima para su funcionamento (hecho 
análogo a la utilización del Convento de los franciscanos en Buenos Aires) com el consiguiente desplazamiento de sus religiosos a otros destinos y la obligación de concurrencia a la Normal de todos los maestros de las escuelas públicas acompanhados de dos discípulos de los más adelantados (López e Narodowski, 1999, p. 57-58).

Além de Thomson, que atuaria também no México, outros missionários do método aportariam na América Latina. O próprio José Lancaster se deslocou até a Colômbia, convidado por Simón Bolivar, que o havia conhecido numa viagem a Londres, ficando encantado com seu método. Lancaster permaneceu em Caracas de 1824 a 1827 em permanente conflito com as autoridades municipais devido à falta de verbas e com as autoridades religiosas, que queriam que Lancaster incluísse em suas escolas o ensino da doutrina cristã. Escrevendo sobre a educação na Colômbia nesse período, o historiador Fernandez Heres, descreve assim o fim que levou essa empreitada:

\begin{abstract}
De Lancaster y su proyecto no quedo nada, sino el recuerdo, y el proprio Revenga [ministro das Relações Exteriores] en mayo de 1829 el informe que dirigió al presidente del Consejo de Ministros, expresaba que ni en esa provincia ni en ninguna otra de estos cuatro departamentos, se encuentra una sola escuela de enseñanza mutua, aunque la ley quiso que las hubiese en todas las especies en todas las parroquias de Colombia (apud López e Narodowski, 1999, p. 60-61).
\end{abstract}

\title{
A recepção no Brasil
}

O ensino mútuo, visto não apenas como um método de ensinar, mas também como uma concepção integral do fenômeno educativo, foi devidamente apropriado pela intelectualidade brasileira nas primeiras décadas do século XIX. Reportando-se à elevação por D. João $\mathrm{VI}$ do Brasil a Reino Unido com Portugal e Algarves, o monarquista Pires de Almeida, em seu pioneiro livro sobre a instrução pública no Brasil, publicado na França em 1889, situa assim a questão da educação:

\begin{abstract}
Depois da elevação do reino do Brasil, os brasileiros passaram a ter o dever de dar aos filhos, não somente a educação moral e a instrução primária ou científica necessárias a todos os homens (uma obrigação) mas também o de lhes inculcar, por assim dizer, na alma nacional este sentimento de fraternidade para com todos os homens do próprio país, que fez a força da nação e assegurou sua independência (...) O projeto de unificação da instrução pública, concebido por D. João VI, fez do corpo dirigente desta organização um representante da unidade nacional no que tange à educação e à instrução propriamente dita (Almeida, 1989, p. 51).
\end{abstract}

Argumentando retrospectivamente, dando por certo que, mais cedo ou mais tarde, a independência viria, Almeida considera que D. João VI, "informador e instigador" do ensino mútuo no Reino, vislumbrou no método a homogeneidade escolar necessária para a construção da nacionalidade. De fato, a lei de 15 de outubro de 1827, a primeira lei da educação do Brasil, tornava obrigatório que nas escolas elementares do país, "em todas as cidades, vilas e lugares mais populosos" se aplicasse o método de ensino mútuo.

Outros autores apontaram a adequação do método à realidade social brasileira pois, além de "abreviar o tempo necessário para a educação das crianças e diminuir 
as despesas das escolas, generaliza a instrução necessária às classes inferiores da sociedade", como se pode ler no jornal mineiro O Universal publicado em 27 de julho de 1925 (apud Faria Filho, 2003, p. 170-171). Como vimos, as "classes inferiores" eram invariavelmente consideradas destinatárias naturais do ensino mútuo, como mostraram cabalmente os aristocratas franceses do Rio de Janeiro ao utilizar o método para instruir escravos. Mais precisamente, as "classes inferiores" visadas pelos propagandistas do método na Europa eram constituídas pelos trabalhadores que precisavam ser disciplinados para colocar em funcionamento o novo modo de produção industrial.

Analisando essa mudança disciplinar, Foucault localiza sua origem nos regulamentos militares que decompunham as operações realizadas pelos soldados para controlar cada movimento e otimizar temporalmente suas ações. Segundo ele, essa "tecnologia" seria gradualmente incorporada pelas atividades humanas:

\begin{abstract}
Por outros meios, a escola mútua também foi disposta como um aparelho para intensificar a utilização do tempo; sua organização permitia desviar o caráter linear e sucessivo do ensino do mestre; regulava o contraponto de operações feitas, ao mesmo tempo, por diversos grupos de alunos sob a direção dos monitores e dos adjuntos, de maneira que cada instante que passava era povoado de atividades múltiplas, mas ordenadas; e por outro lado o ritmo imposto por sinais, apitos, comandos impunha a todos normas temporais que deviam ao mesmo tempo acelerar o processo de aprendizagem e ensinar a rapidez como uma virtude (Foucault, 2012, p. 149).
\end{abstract}

Para corroborar sua análise, o autor de "Vigiar e Punir" cita um relatório dirigido à Sociedade de Ensino Mútuo, onde se explica que a "única finalidade" das instruções dadas durante a aplicação do ensino mútuo é "acostumar as crianças a executar rapidamente e bem as mesmas operações, diminuir tanto quanto possível pela celeridade a perda de tempo acarretada pela passagem de uma operação a outra". Isto era conseguido pelo controle das ações (vigilância) e pela aplicação de sanções ou recompensas (punição) segundo o comportamento observado das crianças. Apesar de não recomendar a aplicação de castigos físicos, em se tratando das "classes inferiores", o método de ensino mútuo ensejava o uso de "castigos de extrema crueldade", como se pode ver na publicação "Castigos Lancasterianos" produzida pelo governo mineiro em 1829 para regulamentar o artigo 15 da lei de 1927 onde se determinava que "os castigos serão os praticados pelo método de Lancaster" (apud Faria Filho e Rosa, 1999, p. 184).

Todavia, a precariedade da ação efetiva do Estado na totalidade do território nacional reduziu a aplicação do método no Brasil, mesmo após a obrigatoriedade imposta pela lei geral do ensino, a experiências esporádicas, marcadas pela improvisação e sem continuidade. Com a descentralização administrativa estabelecida pelo Ato Adicional de !834, que remeteu o ensino elementar aos cuidados das províncias, abriu-se a possibilidade de um ensaio controlado do método num território menor. Para isso, seria necessário também que estivessem no poder políticos representativos dos interesses dominantes na província. Em nenhuma outra província essas condições estavam tão presentes naquele tempo quanto no Rio de Janeiro, consequência do próprio Ato Adicional, que separou geograficamente a cidade do Rio de Janeiro, como município da Corte do restante da província, sem privar os políticos fluminenses do convívio com o poder imperial.

Já em 1835 é criada em Niterói, nova capital da província, uma Escola Normal para formar professores para ensinar a educação elementar por meio do ensino mútuo. Quase vinte anos após, tal como em Portugal, a primeira escola normal no 
Brasil, seria destinada a formar professores de acordo com o ensino mútuo, ambas caudatárias da experiência militar com essa metodologia. Em Niterói, o diretor da escola, que "acumularia as tarefas de professor de todas as disciplinas do currículo, inclusive da parte metodológica", escolhido pelos políticos fluminenses foi o tenentecoronel do exército, José da Costa Azevedo, com largo tirocínio com o ensino mútuo nas fileiras do exército (Villela, 1999, p. 160).

Fundador da Sociedade de Instrução Elementar do Rio de Janeiro, inspirado na associação análoga francesa, Azevedo exerceu plenamente seus deveres como diretor e professor, inclusive fazendo publicar algumas lições suas dadas aos alunos da Escola Normal. A falta de livros didáticos apropriados para os futuros professores já havia compelido a Assembleia provincial a ordenar a tradução e publicação do manual pedagógico do barão de Gérando, Curso Normal para professores de primeiras letras ou direções relativas à educação physica, moral e intelectual nas escolas primárias, vinda a lume em 1839. Publicado na França em 1832 pelo barão, também pertencente à Société pour l'Instruction Élémentaire, da qual foi secretário geral e presidente, esse manual reúne uma série de conferências realizadas na Escola Normal de Paris e, portanto, faz a apologia do ensino mútuo. Todavia, está despido da euforia que acompanhou o ensino mútuo nos primeiros anos com suas prescrições normativas. Na análise de Helena Villela, "a versão do ensino mútuo que é veiculada por esse manual nada tem a ver com as formalidades que comumente caracterizam aquele método" (1999, p. 167).

Essa tentativa orgânica de implantar na província um sistema de ensino fundado no ensino mútuo, ao oferecer seus resultados à consideração dos governantes, membros na época do Partido Conservador (Saquaremas), colimou as críticas negativas que vinham sendo feitas ao método, terminando por proscrevê-lo. O regulamento da instrução primária de 1849 proposto pelo presidente Couto Ferraz é taxativo: "o método de ensino das escolas públicas, será em geral o simultâneo. Poderá, porém, o presidente da província, quando julgar conveniente, mandar que se adote outro em algumas localidades conforme seus recursos e possibilidades" (apud Villela, 1999, p. 108). Embora a província do Rio de Janeiro tenha sido umas das últimas a recusar oficialmente a obrigatoriedade da utilização do ensino intuitivo, o fez com conhecimento de causa.

A identificação dos políticos conservadores da província do Rio de Janeiro, especialmente aqueles beneficiados pela cultura do café no Vale do Paraíba, com os políticos do Império concedeu a essa província uma série de privilégios. Segundo Ilmar Mattos, a administração provincial era o campo imediato de aplicação dos projetos do Império,

cumprindo o papel de um laboratório, no qual os Saquaremas tanto testavam medidas e avaliavam ações que buscavam estender à administração geral, quanto aplicavam decisões do Governo-Geral, sempre com a finalidade última de consolidar a ordem no Império (Mattos, 1994, p. 240).

De fato, o mesmo presidente do Rio de Janeiro, Couto Ferraz, que praticamente abolira o ensino mútuo em sua província, agora como Ministro do Império, baixaria em fevereiro de 1854 um decreto que regulamentava o ensino primário e secundário no Município da Corte, a primeira grande reforma de nosso ensino. Embora a reforma se destinasse inicialmente à cidade do Rio de Janeiro, esperava-se que essa iniciativa servisse de modelo para impulsionar a reforma do ensino em todas as províncias brasileiras. 


\title{
Conclusão
}

Ao finalizar seu trabalho sobre o ensino mútuo na província do Rio de Janeiro, Heloisa Villela elenca a possível influência deixada por esse ensino não só na região, mas também na educação brasileira em geral devido à difusão nacional da experiência de sua Escola Normal:

\begin{abstract}
Ela pode ser encontrada nas formas mistas de ensinar que percorreram todo aquele período até que, já no século XX, fossem experimentadas as divisões de turmas por nível de adiantamento na lógica dos grupos escolares. Ela pode estar também nas concepções de arranjo do tempo e do espaço escolar, na utilização de materiais de ensino, na veiculação de ideias nos compêndios pedagógicos. Mas, sobretudo, podemos sentir essa influência nas representações de escola e de como fazer a educação, expressas em leis, regulamentos e estatutos da época (Villela, 1999, p. 173-174).
\end{abstract}

Neste sentido, ao tomar o ensino mútuo como padrão nacional de ensino, a lei de 15 de outubro de 1827 (dia em que se comemora o Dia do Professor no Brasil), expressa em todos seus artigos essa concepção educativa. Assim, por exemplo, o seu artigo $5^{\circ}$ determinava que "para as escolas de ensino mútuo se aplicarão os edifícios que houverem com suficiência nos lugares delas, arranjando-se com os utensílios necessários à custa da Fazenda Pública", influindo diretamente na definição do espaço escolar. Como naquela época a maioria das aulas de primeiras letras se davam nas casas dos professores e como, em princípio, o método exigia grandes espaços, a lei abria a possibilidade de se alugarem espaços mais adequados para 0 funcionamento das escolas. Aqui, ao contrário da experiência de outros países latinoamericanos, não se tem notícia do uso de conventos ou outras dependências da Igreja para instalar escolas de ensino mútuo. Cardoso, que estudou essa questão no caso do Rio de Janeiro concluiu que "na prática, isso significava que o aluguel dos imóveis onde se estabeleciam as aulas do ensino mútuo era pago pelo governo" (1999, p. 134), contribuindo assim para que a escola elementar se tornasse pública ao viabilizar a disposição constitucional de que a instrução primária fosse gratuita.

Também se pode atribuir ao ensino mútuo o reforço de certas características presentes até hoje na prática de ensino. A extensão da relação tutorial professor/aluno por meio da criação da figura do monitor seria introduzida na prática de ensino e, inclusive, daria origem à categoria de professor adjunto, vista inicialmente como treinamento em serviço. Por outro lado, como confirmado pela psicologia da educação do século $X X$, ao valorizar a aprendizagem decorrente da interação entre os estudantes, o ensino mútuo colocou em evidência esse importante princípio educativo: aprender com quem também está aprendendo ou que tenha acabado de aprender. A ênfase no aprendizado dos alunos entre si, nos permite incluir aqui também o trabalho em grupo como um desdobramento da organização dos alunos em decúrias promovida pelo método.

Porém, mais do que sua influência na estrutura e funcionamento do ensino, o método de ensino mútuo forneceu um padrão unitário para a escolarização do povo da nova nação que se formava. Estimulada pela iniciativa privada, a ideia do ensino mútuo seria rapidamente apropriada pelo Estado, não por acaso inicialmente no exército, para se estender depois, por meio da lei geral de ensino de 1827, a todo o país. Todavia, gerado em função do desenvolvimento industrial em países europeus 
o ensino mútuo não seria assimilado organicamente pela sociedade brasileira. Tanto é que após a descentralização administrativa imposta pelo Ato Adicional de 1834, como vimos, apenas a província do Rio de Janeiro ensaiou regular sistematicamente seu ensino elementar por meio do método, dada apenas pela sua proximidade da Corte, onde a ideia do ensino mútuo circulava mais intensamente.

\section{Referências}

Alves, C.M.C. (2003). A presença militar na educação do século XIX. In: Alves, C.M.C.; Gondra, J.G.; Magaldi, A.M. (Org.). Educação no Brasil: história, cultura e política. Bragança Paulista: EDUSF, p. 227-251.

Bastos, M.H.C. e Faria Filho, L.M. (Org.) (1999). A escola elementar no século XIX: o método monitorial/mútuo. Passo Fundo: Ediupf.

Cardoso, T.M.F. (1999). Abrindo um novo caminho. O ensino mútuo na escola pública do Rio de Janeiro (1823-1840). In: Bastos, M.H.C. e Faria Filho, L.M. (Org.). A escola elementar no século XIX: o método monitorial/mútuo. Passo Fundo: Ediupf, p. 118143.

Carvalho, R. (2011). História do Ensino em Portugal. 5. ed. Lisboa: Fundação Calouste Gulbenkian.

Chizzotti, A. (1996). A constituinte de 1823 e a educação. In: Fávero, O. (Org.). A educação nas constituintes brasileiras (1823-1988). Campinas/SP: Autores Associados, p. 31-53.

Conde, M.T.B. (2005). O Modo de Ensino Mútuo na Formação dos Mestres de Primeiras Letras. Uma Experiência Pedagógica no Portugal Oitocentista. Revista Lusófona de Educação, 6, p. 117-137.

Cury, C.A.J. (2018). Financiamento da educação brasileira: do subsídio literário ao FUNDEB. Educação \& Realidade. Porto Alegre, v. 43, n. 4, p. 1217-1252.

Faria Filho, L.M.; Rosa, W.M. (1999). O ensino mútuo em Minas Gerais (1823-1842). In: Bastos, M.H.C. e Faria Filho, L.M. (Org.). A escola elementar no século XIX: o método monitorial/mútuo. Passo Fundo: Ediupf, p. 177-196.

Faria Filho, L.M. (2003). Educação do povo e autoritarismo das elites: instrução pública e cultura política no século XIX. In: Alves, C.M.C.; Gondra, J.G.; Magaldi, A.M. (Org.). Educação no Brasil: história, cultura e política. Bragança Paulista: EDUSF, p. 171-182.

Fernandes, R. (1999). A difusão do ensino mútuo em Portugal no começo do século XIX. In: Bastos, M.H.C. e Faria Filho, L.M. (Org.). A escola elementar no século XIX: o método monitorial/mútuo. Passo Fundo: Ediupf, p. 25-44.

Lins, A.M.M. (1999). O método Lancaster: educação elementar ou adestramento. Uma proposta pedagógica para Portugal e Brasil no século XIX. In: Bastos, M.H.C. e Faria Filho, L.M. (Org.). A escola elementar no século XIX: o método monitorial/mútuo. Passo Fundo: Ediupf, p. 71-93.

López, C. e Narodowski (1999). El mejor de los métodos posibles. La introducción del método lancasteriano em Iberoamérica em el temprano siglo XIX. In: Bastos, M.H.C. e Faria Filho, L.M. (Org.). A escola elementar no século XIX: o método monitorial/mútuo. Passo Fundo: Ediupf, p. 45-72. 
Mattos, I. R. (1994). O tempo Saquarema. São Paulo: Hucitec.

Neves, L.M.B.P. (2014). Ler, contar e escrever: educação e livros no Rio de Janeiro joanino (1808-1821). História: Questões \& Debates. Curitiba, n. 60, p. 163-188.

Tonholli, D.A. (2010). A instrução pública no Brasil entre 1808 e 1834: levantamento $e$ análise da legislação. Dissertação (Mestrado em Educação - PUC/Minas). Belo Horizonte, 2010

Valente, W.R. (1999) Uma história da matemática escolar no Brasil (1730 - 1930). São Paulo: Annablume; FAPESP.

Villela, H. (1999). O ensino mútuo na origem da primeira escola normal do Brasil. In: Bastos, M.H.C. e Faria Filho, L.M. (Org.). A escola elementar no século XIX: o método monitorial/mútuo. Passo Fundo: Ediupf, p. 145-176. 